\title{
Development of Heat Hyperalgesia and Changes of TRPV1 and NGF Expression in Rat Dorsal Root Ganglion Following Joint Immobilization
}

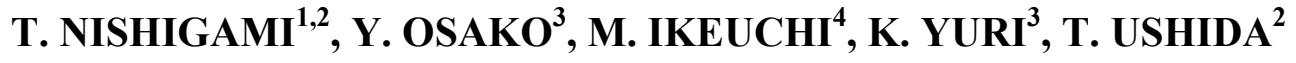 \\ ${ }^{1}$ Department of Physical Therapy, Konan Woman's University, Kobe, Japan, ${ }^{2}$ Multidisciplinary \\ Pain Center, Aichi Medical University, Nagakute, Japan, ${ }^{3}$ Department of Neurobiology and \\ Anatomy, Kochi Medical School, Nankoku, Japan, ${ }^{4}$ Department of Orthopedic Surgery, Kochi \\ Medical School, Nankoku, Japan
}

Received November 7, 2011

Accepted November 2, 2012

On-line December 13, 2012

\begin{abstract}
Summary
The aim of this study was to examine whether threshold to heat stimuli, and expression of transient receptor potential vanilloid1 (TRPV1) and nerve growth factor (NGF) in dorsal root ganglion (DRG) altered under conditions of long-term limb immobilization. A plastic cast was wrapped around the right limb from the forearm to the forepaw to keep wrist joint at $90^{\circ}$ of flexion for 5 weeks. Heat hyperalgesia was tested using the plantar test at $6 \mathrm{~h}$ after removing cast. The rats were perfused transcardially with $4 \%$ paraformaldehyde and DRGs were excised at $24 \mathrm{~h}$ after removing cast. For size distributions of the TRPV1-IR and NGF-IR neuronal profile, the DRG area measurements over 1000 DRG neurons per animal were measured in each side, on both the immobilized (ipsilateral) and contralateral sides. Ipsilateral withdrawal latency was significantly shorter than contralateral sides. Ipsilateral percentage of immunoreactive neurons in the total DRG neurons was significantly higher than contralateral sides in TRPV1-IR and NGF-IR. Long-term casting induced heat hyperalgesia, and up-regulation and phenotypic change of TRPV1-IR and NGF-IR in DRGs on the immobilized side. These DRG alterations may involve heat hyperalgesia after long-term limb immobilization.
\end{abstract}

\section{Key words}

Long-term immobilization • Pain • Heat hyperalgesia • Transient receptor potential vanilloid1 • Dorsal root ganglion

\begin{abstract}
Corresponding author
T. Ushida, Multidisciplinary Pain Center, Aichi Medical University, Nagakute, Aichi 480-1195, Japan. Fax: +81 56162 5004. E-mail: ushidat-koc@umin.ac.jp
\end{abstract}

Joint immobilization by casting is commonly utilized for local resting after fracture. Allen and colleagues proposed that immobilization by cast or splint may play a role in the development of complex regional pain syndrome (CRPS), known as chronic pain (Allen et al. 1999). It has been reported that limb immobilization by casting alone (without a fracture) could induce similar symptoms and sign of CRPS in human and animal experimental study (Guo et al. 2004, Terkelsen et al. 2008). We previously developed a longterm joint immobilization model, which showed a joint contracture in the affected limb, and observed changes in electrophysiological responses of dorsal horn neurons to mechanical and motion stimuli (Ushida and Wills 2001). More recently, we detected phenotypic changes in calcitonin gene-related peptide (CGRP) expression both in dorsal root ganglion (DRG) and spinal deep layers in immobilized side (Nishigami et al. 2009). Our results suggested that long-term immobilization by casting changes function and chemical coding in DRG and spinal dorsal horn neurons, and these changes are partly responsible for pathological pain states in 
immobilized side.

Transient receptor potential vanilloid1 (TRPV1) and nerve growth factor (NGF) are implicated as key molecules in development and persistence of pain disorder particularly heat hyperalgesia. Heat hyperalgesia is largely absent in mice lacking TRPV1 (Caterina et al. 2000), and TRPV1 is up-regulated in DRG of inflammation and nerve injury models, which showed heat hyperalgesia (Fukuoka et al. 2002, Amaya et al. 2003). The level of NGF was elevated at inflammation site, retrograde transport of NGF to the DRG from the inflamed site up-regulated various pain-related molecules such as CGRP and brain-derived neurotrophic factor (BDNF) (Donnerer et al. 1992, Cho et al. 1997), and led to hypersensitivity to heat. Therefore, we postulate that immobilization induces heat hyperalgesia as a result of TRPV1 and/or NGF up-regulation. The aim of the present study is to examine alternation of threshold to heat stimuli and expression of TRPV1 and NGF in DRG after long-term immobilization.

All procedures used in these experiments were approved by the Konan Woman's University Animal Care and Use Committee and were consistent with the guidelines of the International Association for the Study of Pain for the care and use of laboratory animals. Fourteen adult male Sprague-Dawley rats (250-300 g; Japan SLC, Inc.) were used in this study. Long-term joint immobilization was maintained by using a plastic cast as described previously (Ushida and Wills 2001). The rats were anesthetized with tribromoethanol $(200 \mathrm{mg} / \mathrm{kg}$ i.p.), and a plastic cast was wrapped around the right limb from the forearm to the forepaw to keep wrist joint at $90^{\circ}$ of flexion for 5 weeks.

Heat hyperalgesia was tested using the plantar test at $6 \mathrm{~h}$ after removing cast. Latency until the rat lifted the forepaw was recorded. The measurements of latency were taken at least fourth times in each forepaw and alternatively with longer than $3 \mathrm{~min}$ intervals between consecutive tests. The measurements of latency per side were averaged.

At $24 \mathrm{~h}$ after removing cast, the six rats were perfused transcardially with $4 \%$ paraformaldehyde and C7 to C8 levels DRGs, which innervate the wrist joint in the rat, were excised and used for immunohistochemistry. All of the sections were cut on a cryostat at a thickness of $12 \mu \mathrm{m}$, incubated in the primary antibody to TRPV1 (1:1000, Alomone Lab, Israel) or NGF (1:1000, Abcam, UK) for $48 \mathrm{~h}$ at $4{ }^{\circ} \mathrm{C}$, incubated in biotinated anti-rabbit $\mathrm{IgG}$ from goat $(1: 1000$, Vector Labs, $\mathrm{UK})$ for $2 \mathrm{~h}$ at room temperature, and incubated in avidin-biotin complex (1:100, Vector Labs, UK). All of the sections were visualized using diaminobenzidine staining.

Ten sections in ipsilateral and contralateral DRGs were extracted per animal at random for analysis. The ratio of TRPV1-IR and NGF-IR neurons to total number of neurons were calculated in each side. For size distributions of the TRPV1-IR and NGF-IR neuronal profile, the DRG area measurements over 1000 DRG neurons per animal were measured in each side, on both the immobilized (ipsilateral) and contralateral sides, using imaging analysis software (NIH Image). Only immunoreactive neurons with visible nuclei were selected for measurement. The area measurements were performed blindly by using randomized sets of digital photos of DRGs.

The data were expressed as median and interquartile range. The differences in latency of hot plantar test and in the number of immunoreactive neurons between the ipsilateral and contralateral sides were assessed using Mann-Whitney's U test. The differences in size distribution of immunoreactive neurons were assessed using Mann-Whitney's U test for each $300 \mu \mathrm{m}^{2}$ size. Statistically significant differences between groups were expressed as $p$ values less than $0.05(p<0.05)$.

Ipsilateral withdrawal latency was significantly shorter than contralateral sides $(4.9,4.1-5.2 \mathrm{~s}$ vs 6.0 , 5.7-6.6 s). Ipsilateral percentage of immunoreactive neurons in the total DRG neurons were significantly higher than contralateral sides in TRPV1-IR and NGF-IR (Fig. 1A and 2A: TRPV1; 33.6, 30.6-35.8\% vs 23.5, 22.0-27.8 \%: NGF; 34.0, 30.0-35.9 \% vs 23.5, 21.7$24.5 \%$ ). The TRPV1-IR and the NGF-IR cell size in ipsilateral side significantly increased in $300-600 \mu \mathrm{m}^{2}$ compared to contralateral side (Fig. 1B and 2B).

The present study revealed that long-term immobilization by casting induced heat hyperalgesia and an up-regulation and the shift in the size distribution of TRPV1-IR and NGF-IR neurons in DRGs. Up-regulation of TRPV1 expression and phenotypic changes of TRPV1-IR neurons from small to medium-size lumbar DRG neurons which are myelinated A-delta fibers were observed after inflammation, suggesting that A-delta fibers in DRG neurons might contribute to the development and maintenance of inflammatory hyperalgesia (Amaya et al. 2003, Luo et al. 2008). In the present study, the ratio of TRPV1-IR neurons at the ipsilateral side reached about 1.5 -fold the contralateral side and the $300-600 \mu \mathrm{m}^{2}$ size immunoreactive neurons 


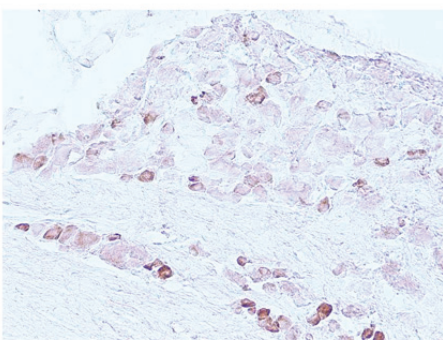

Contralateral side
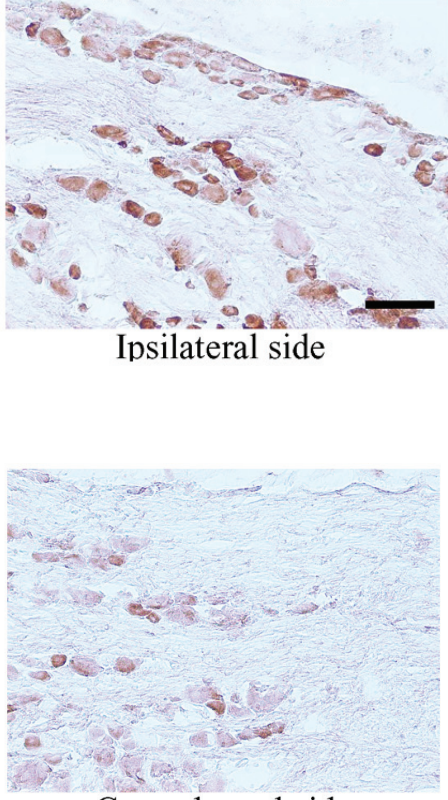

Contralateral side

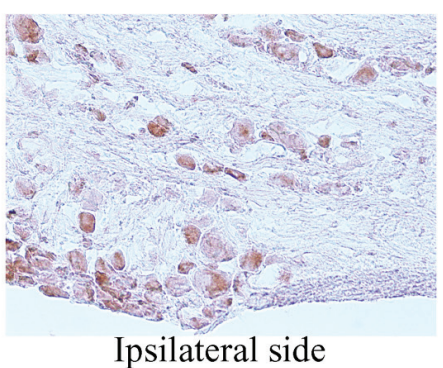

A

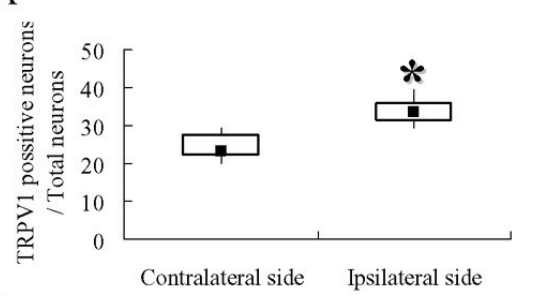

$\mathrm{B}$

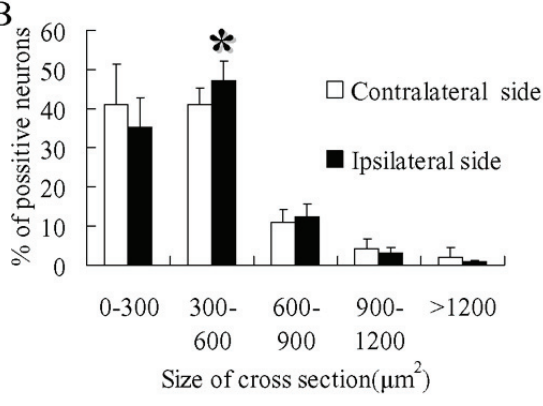

A

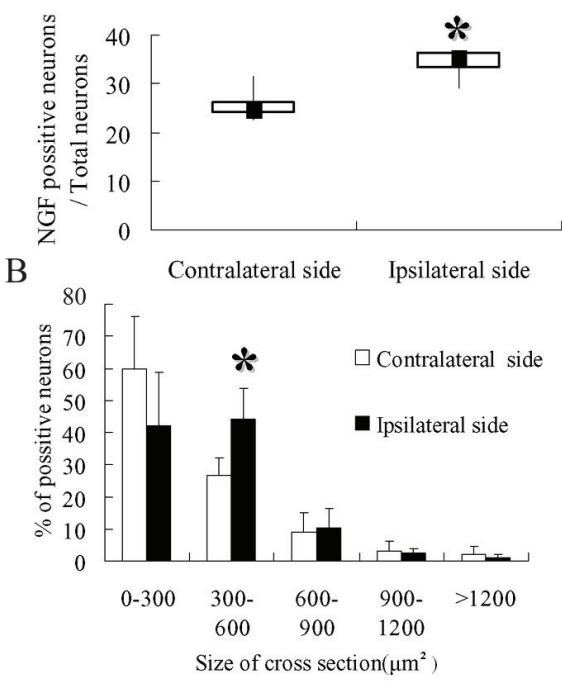

Fig. 1. Significant differences in the number of TRPV1-IR DRG neurons to total neurons were found between ipsilateral and contralateral sides (A) The TRPV1-IR cell size on the ipsilateral side significantly increased in $300-600 \mu \mathrm{m}^{2}$ compared to contrateral side (B). ${ }^{*} \mathrm{p}<0.05$.
Fig. 2. Significant differences in the number of NGF-IR DRG neurons to total neuron were found between ipsilateral and contralateral sides (A). The NGF-IR cell size on the ipsilateral side significantly increased in $300-600 \mu \mathrm{m}^{2}$ compared to contrateral side (B). ${ }^{*} p<0.05$. were prominent. Although it is unclear which A-delta fibers and corresponding size of cervical DRG neurons are, long-term forelimb immobilization might up-regulate TRPV1 mainly in A-delta fibers like inflammation.

Similar changes (up-regulation and alternation in size distribution) were detected in the NGF expression in DRG neurons. NGF seems to have important functional significance in the development of heat hyperalgesia in conjunction with TRPV1, because heat hyperalgesia induced by injection of NGF is largely absent in TRPV1 null mice (Chuang et al. 2001). Therefore, TRPV1 expression might be induced by NGF expression. NGF is induced by inflammation and nerve injury in the rat (Donnerer et al. 1992, Obata et al. 2004). Previous studies have reported that immobilization induced marked inflammatory changes in synovium and primary inflammatory reaction (Michelsson and Hunneyball 1984, Konttinen et al. 1990). Considering these results, longterm casting might induce the inflammation and increase of NGF-IR neurons in the current immobilization model.

We have previously demonstrated that the population of wide dynamic range (WDR) neurons in the spinal deep layers on the immobilized side increased in this immobilized model (Ushida and Wills 2001). TRPV1 receptor antagonist inhibited heat hyperalgesia and electrical response of WDR neurons in the deep layers on day 1 and 14 after inflammation (Luo et al. 2008). Furthermore, systematic administration of TRPV1 receptor antagonist reduced the spontaneous firing of WDR neurons in inflammatory rat (McGaraughty et al. 2008). These results raise the possibility that an increase of TRPV1-IR in DRGs induce heat hyperalgesia through 
WDR neuronal activation after long-term immobilization.

In conclusion, long-term casting induced heat hyperalgesia, up-regulation and phenotypic change of TRPV1-IR and NGF-IR in DRGs on the immobilized side. These DRG alterations may be involved in heat hyperalgesia after long-term limb immobilization.

\section{Conflict of Interest}

There is no conflict of interest.

\section{Acknowledgements}

This study was supported by a grant-in-aid for scientific research (No. 22390924) from the Japan Society for the Promotion of Science.

\section{References}

ALLEN G, GALER BS, SCHWARTZ L: Epidemiology of complex regional pain syndrome: a retrospective chart review of 134 patients. Pain 80: 539-544, 1999.

AMAYA F, OH-HASHI K, NARUSE Y, IIJIMA N, UEDA M, SHIMOSATO G, TOMINAGA M, TANAKA Y, TANAKA M: Local inflammation increases vanilloid receptor 1 expression within distinct subgroups of DRG neurons. Brain Res 963: 190-196, 2003.

AMAYA F, SHIMOSATO G, NAGANO M, UEDA M, HASHIMOTO S, TANAKA Y, SUZUKI H, TANAKA M: NGF and GDNF differentially regulate TRPV1 expression that contributes to development of inflammatory thermal hyperalgesia. Eur J Neurosci 20: 2303-2310, 2004.

CATERINA MJ, LEFFLER A, MALMBERG AB, MARTIN WJ, TRAFTON J, PETERSEN-ZEITZ KR, KOLTZENBURG M, BASBAUM AI, JULIUS D: Impaired nociception and pain sensation in mice lacking the capsaicin receptor. Science 288: 306-313, 2000.

CHO HJ, KIM SY, PARK MJ, KIM DS, KIM JK, CHU MY: Expression of mRNA for brain-derived neurotrophic factor in the dorsal root ganglion following peripheral inflammation. Brain Res 749: 358-362, 1997.

CHUANG HH, PRESCOTT ED, KONG H, SHIELDS S, JORDT SE, BASBAUM AI, CHAO MV, JULIUS D: Bradykinin and nerve growth factor release the capsaicin receptor from PtdIns(4,5)P2-mediated inhibition. Nature 411: 957-962, 2001.

DONNERER J, SCHULIGOI R, STEIN C: Increased content and transport of substance P and calcitonin gene-related peptide in sensory nerves innervating inflamed tissue: evidence for a regulatory function of nerve growth factor in vivo. Neuroscience 49: 693-698, 1992.

FUKUOKA T, TOKUNAGA A, TACHIBANA T, DAI Y, YAMANAKA H, NOGUCHI K: VR1, but not P2X(3), increases in the spared L4 DRG in rats with L5 spinal nerve ligation. Pain 99: 111-120, 2002.

GUO TZ, OFFLEY SC, BOYD EA, JACOBS CR, KINGERY WS: Substance P signaling contributes to the vascular and nociceptive abnormalities observed in a tibial fracture rat model of complex regional pain syndrome type I. Pain 108: 95-107, 2004.

KONTTINEN YT, MICHELSSON JE, TOLVANEN E, BERGROTH V: Primary inflammatory reaction in synovial fluid and tissue in rabbit immobilization osteoarthritis. Clin Orthop Relat Res 260: 280-286, 1990.

LUO H, XU IS, CHEN Y, YANG F, YU L, LI GX, LIU FY, XING GG, SHI YS, LI T, HAN JS, WAN Y: Behavioral and electrophysiological evidence for the differential functions of TRPV1 at early and late stages of chronic inflammatory nociception in rats. Neurochem Res 33: 2151-2158, 2008.

MCGARAUGHTY S, CHU KL, BROWN BS, ZHU CZ, ZHONG C, JOSHI SK, HONORE P, FALTYNEK CR, JARVIS MF: Contributions of central and peripheral TRPV1 receptors to mechanically evoked and spontaneous firing of spinal neurons in inflamed rats. J Neurophysiol 100: 3158-3166, 2008.

MICHELSSON JE, HUNNEYBALL IM: Inflammatory involvement in rabbit knee following immobilization and resulting in osteoarthritis. Scand J Rheumatol 13: 273-281, 1984.

NISHIGAMI T, OSAKO Y, TANAKA K, YURI K, KAWASAKI M, IKEMOTO T, MCLAUGHLIN M, ISHIDA K, TANI T, USHIDA T: Changes in calcitonin gene-related peptide expression following joint immobilization in rats. Neurosci Lett 454: 97-100, 2009. 
OBATA K, YAMANAKA H, DAI Y, MIZUSHIMA T, FUKUOKA T, TOKUNAGA A, YOSHIKAWA H, NOGUCHI K: Contribution of degeneration of motor and sensory fibers to pain behavior and the changes in neurotrophic factors in rat dorsal root ganglion. Exp Neurol 188: 149-160, 2004.

TERKELSEN AJ, BACH FW, JENSEN TS: Experimental forearm immobilization in humans induces cold and mechanical hyperalgesia. Anesthesiology 109: 297-307, 2008.

USHIDA T, WILLS WD: Changes in dorsal horn neuronal responses in an experimental wrist contracture model. J Orthop Sci 6: 46-52, 2001. 